\title{
Effects of parasitoid associated factors of the endoparasitoid Glyptapanteles liparidis (Hymenoptera: Braconidae)
}

\author{
Nicole A. TILLINGER, GeRnot HOCH and AXeL SCHOPF \\ Institute of Forest Entomology, Forest Pathology and Forest Protection, BOKU - University of Natural Resources and Applied Life \\ Sciences, Hasenauerstraße 38, 1190 Vienna, Austria; e-mail: hoch@ento.boku.ac.at
}

Key words. Glyptapanteles liparidis, parasitoid, polydnavirus, venom, pseudoparasitization, Lymantria dispar, gamma irradiation, immune suppression, larval development

\begin{abstract}
The endoparasitoid Glyptapanteles liparidis (Hymenoptera: Braconidae) injects polydnavirus and venom together with eggs into its Lymantria dispar (Lepidoptera: Lymantriidae) host larvae during oviposition. We studied effects of these parasitoid associated factors by means of $\gamma$-irradiation-induced pseudoparasitization. The application of radiation for sterilization of female wasps as a tool to study interactions between parasitoid associated factors and the host is demonstrated in this paper. When wasps were irradiated at doses ranging from 24 to 96 Gy and then allowed to oviposit into L. dispar larvae, temporary sterilization was produced. On the first day post irradiation they laid $99 \%$ sterile eggs, but fertility recovered partially during the following days. Irradiation had no negative effect on the lifespan of wasps, but total fecundity was significantly reduced. Pseudoparasitization of $L$. dispar by irradiated $G$. liparidis caused prolonged larval development with supernumerary molts before pupation in females, and higher pupal weights in both sexes. Only 8 to $20 \%$ of pseudoparasitized larvae developed into adults; 20 to $33 \%$ died as larvae, 55 to $65 \%$ in pupae. Abnormities, such as precocious formation of pupal antennal pads in larvae or incomplete sclerotization of pupal cuticle occurred. Pseudoparasitization impaired the immune reactions of $L$. dispar larvae. Encapsulation of implanted plastic rods by hemocytes was reduced and hemolymph melanization was significantly suppressed 3 and 5 days post pseudoparasitization.
\end{abstract}

\section{INTRODUCTION}

The braconid wasp Glyptapanteles liparidis (Bouche) (Hymenoptera: Braconidae) is a gregarious endoparasitoid of Lymantria dispar (L.) (Lepidoptera: Lymantriidae) larvae. In Eastern Austria's oak forests, it is one of the dominant natural enemies of $L$. dispar, and may play an important role in population dynamics of this forest pest (Schopf \& Hoch, 1997; Hoch et al., 2001). The wasp parasitizes young to mid-stage larvae; depending on host size at time of oviposition, females lay 5 to 50 eggs into the host's hemocoel. Parasitoid larvae develop through two endoparasitic instars, feeding exclusively on host hemolymph. After two to three weeks, the endoparasitic development is completed and larvae emerge from the host while molting to the third instar. Then, they spin their cocoons for pupation next to the host larva which stays alive for a further few days, not capable of feeding and coordinated movements (Schopf, 1991; Schopf \& Steinberger, 1996; Schopf \& Hoch, 1997).

Parasitoid associated factors support the endoparasitic development of $G$. liparidis like in many other braconids. Particles of a symbiotic polydnavirus (PDV) that replicates in the calyx region of the wasp's ovary together with venom are injected into the hemocoel of the host during oviposition. In several other host-parasitoid systems, these substances have been shown to play a crucial role in preventing encapsulation and damage of the parasitoid progeny by impairing both the host's humoral as well as cellular defense mechanisms (e.g. Edson et al., 1981; Lavine \& Beckage, 1995; Strand \& Pech, 1995; Shelby \& Webb, 1999). Moreover, parasitoid associated factors can play an important role in influencing host development (reviewed in Lawrence \& Lanzrein, 1993; Beckage, 1997). In a previous study, we demonstrated effects of $G$. liparidis PDV and venom on the development of host larvae infected with entomopathogenic microsporidia (Hoch \& Schopf, 2001). Possible origin and co-evolution of PDV have recently been reviewed by Whitfield \& Asgari (2003) and Federici \& Bigot (2003).

Jones (1985) reported on pseudoparasitism in Trichoplusia ni hosts stung by Chelonus sp. wasps, which showed symptoms typical for parasitization, like precocious initiation of metamorphosis, but did not contain obvious or living parasitoids at that time. Soller \& Lanzrein (1996) employed x-rays to sterilize female Chelonus inanitus to study effects of polydnavirus and venom without developing parasitoids; i.e. in cases of artificial pseudoparasitism. Radiation sterilized the eggs within the ovary so that these wasps oviposited infertile eggs along with PDV and venom into the host. One advantage of this method in comparison to injection of purified PDV and venom is that it reflects the natural situation of parasitism as far as amount of injected parasitoid associated substances and minimal impact on the host larva during the process of injection are concerned. A disadvantage is that PDV and venom can only be applied together. In our study, we tested $\gamma$-irradiation-induced pseudoparasitization of $G$. liparidis wasps for investigating effects on $L$. dispar host larvae. Wasps were exposed to different doses of radiation in a cobalt irradiator and allowed to (pseudo-) parasitize $L$. dispar larvae. Gamma radiation from cobalt sources is normally used in sterile insect programs; here we demonstrate its application as a tool to study interac- 
tions between the braconid endoparasitoid and its host larva. Host development was monitored and host immune reactions were analyzed; we assayed hemocytic encapsulation by implantations of plastic rods and measured hemolymph melanization due to activation of prophenoloxidase. In addition, the effect of $\gamma$-irradiation on the wasps was studied; we recorded life span and egg production as well as recovery of production of fertile eggs.

\section{MATERIAL AND METHODS}

\section{Insects}

L. dispar larvae were obtained from egg masses provided by the USDA/APHIS Otis Methods Development Center at Cape Cod, MA, USA. Larvae were reared on high wheat germ diet (Bell et al., 1981) either in groups in $250 \mathrm{ml}$ plastic cups or individually in $40 \mathrm{ml}$ plastic cups at $20^{\circ} \mathrm{C}$ and $16 \mathrm{~L}$ : 8D photoperiod.

G. liparidis were obtained from our laboratory colony, originating from parasitized $L$. dispar collected in oak forests in Burgenland, Austria. Adult wasps were reared on water and honey at $15 / 10^{\circ} \mathrm{C}$ and $16 \mathrm{~L}: 8 \mathrm{D}$ photoperiod unless otherwise indicated. To achieve parasitization, host larvae were offered to wasps with a pair of forceps until the sting occurred.

Irradiation of $G$. liparidis wasps was performed in a Gammacell 220 Co60 irradiator at the FAO/IAEA Agriculture and Biotechnology Laboratories, Seibersdorf, Austria. For the treatment, wasps were placed in ventilated $6 \times 6 \times 8 \mathrm{~cm}$ plastic boxes in groups of 10 to 15 . Doses used in the various experiments ranged from 24 to $96 \mathrm{~Gy}$ at dose-rates of 26.6 to 28.8 Gy/min.

\section{Effects of irradiation on G. liparidis}

G. liparidis females were irradiated with doses of 48 and 96 Gy, respectively, 7 to 8 days after eclosion from the cocoon. After the treatment, wasps were reared individually at $20^{\circ} \mathrm{C}$ and $16 \mathrm{~L}: 8 \mathrm{D}$ photoperiod; non-irradiated females of the same age served as controls. Beginning on day 1 post irradiation, the $G$. liparidis wasps were allowed to parasitize up to $3 \mathrm{~L}$. dispar larvae every third day until they died. To quantify oviposition as well as successful sterilization, host larvae were dissected 5 or more days after parasitization and checked for the presence of parasitoid eggs and/or larvae under the dissecting microscope.

\section{Effects of pseudoparasitization on $\boldsymbol{L}$. dispar development}

G. liparidis females were irradiated with doses of 24,48 , and 96 Gy ( 22 wasps at each dose), respectively, 7 to 8 days after eclosion from the cocoon; non-irradiated females of the same age served as controls. One day post irradiation each wasp was allowed to parasitize 2 to $4 \mathrm{~L}$. dispar larvae in premolt to $3 \mathrm{rd}$ instar (indicated by slippage of head capsule). Larvae were reared individually in $40 \mathrm{ml}$ cups, weighed and checked daily; molts, pupation, adult eclosion, parasitoid emergence, or death were recorded. Pupae were weighed on the 3rd day after the larval-pupal molt.

\section{Effects of pseudoparasitization on host immune system}

$L$. dispar larvae in premolt to the 4th instar were pseudoparasitized by $G$. liparidis that had been irradiated at 48 Gy the day before or parasitized by untreated wasps. Unparasitized larvae served as controls.

Hemocytic encapsulation. After the molt to 4th instar (i.e., 2 days post parasitism), plastic rods $(1.96 \pm 0.21 \mathrm{~mm} \times 0.34 \pm$ $0.01 \mathrm{~mm}$ ) were implanted into the larvae. Larvae were sedated on ice for $20 \mathrm{~min}$ and surface-disinfected with $70 \%$ ethanol. A small cut was made on the base of the second proleg with ocular scissors; three plastic rods were inserted into the hemocoel through this opening. The rods had been disinfected in $70 \%$ ethanol and rinsed in distilled water before implantation. Larvae were put in sterile Petri dishes and transferred to fresh diet one day after implantation. Five days later, the larvae were dissected and the plastic rods were recovered. All rods that were found free in the hemocoel were used for analysis, whereas rods that were stuck in adipose tissue or the larval integument were excluded. For analysis, the rods were transferred onto a microscope slide in insect saline and photographed at $40 \times$ magnification under bright field microscopy. The digital images were analyzed with the program LUCIA 32G (Laboratory Imaging); projected area of the rod as well as the hemocyte capsule were measured, the approximated volume of the capsule was calculated.

Hemolymph melanization. Hemolymph samples were collected from an other group of larvae 3,5, and 11 days post parasitism and melanization due to activation of the prophenoloxidase system was assayed photometrically. Therefore, one proleg of a $L$. dispar larva was cut and $20 \mu \mathrm{l}$ hemolymph were collected with a micro capillary pipette. Each sample was transferred immediately into a $3-\mathrm{ml}$ polystyrene cuvette containing $2980 \mu \mathrm{l}$ reaction mix consisting of $2480 \mu \mathrm{l}$ reaction buffer (Sörensen's phosphate buffer, $\mathrm{pH} 7.2$ in $1: 3$ dilution in Ringer's saline; after Willers \& Lehmann-Danzinger, 1984) and $500 \mu 1$ $0.1 \%$ L-3,4-dihydroxyphenylalanine (L-DOPA) solution in reaction buffer. The absorbance of the mixture was measured in a LKB Biochrom Ultrospec II spectrophotometer at $405 \mathrm{~nm}$ every $5 \mathrm{~min}$ until $40 \mathrm{~min}$. The analyses were done at laboratory room temperature $\left(23 \pm 2{ }^{\circ} \mathrm{C}\right)$.

\section{Statistical analysis}

Statistical analyses were carried out with SPSS 8.0 for Windows (SPSS Inc., 1997). Data were analyzed for normal distribution with Kolmogorov-Smirnov Z test. Means of normally distributed data were compared by one-way ANOVA, and post hoc analyzed by Scheffe test (homogeneity of variances) or Tamhane's T2 (no homogeneity of variances). Comparisons of two means of normally distributed data were carried out by Student's $t$ test. Data lacking normal distribution were compared by Kruskal-Wallis $\mathrm{H}$ test followed by pairwise comparisons by Mann-Whitney U tests (controlled for type I errors after the Bonferroni method). Relative frequencies were compared by Chi square cross-table analysis.

\section{RESULTS}

\section{Effects of irradiation on G. liparidis}

Irradiation had no significant effect on the lifespan of G. liparidis females. When treated with $48 \mathrm{~Gy}$, wasps died $20.0 \pm 2.3$ d post irradiation $(n=22)$, after receiving a dose of $96 \mathrm{~Gy}$, they died $15.7 \pm 1.8 \mathrm{~d}$ post irradiation (n $=22$ ), while untreated females died after $15.5 \pm 2.2 \mathrm{~d}(\mathrm{n}=$ 12). However, $\gamma$-radiation induced a significant reduction of oviposition. Already in the first days post treatment, controls laid about 4 times as many eggs as irradiated wasps. In both treated groups egg production decreased rapidly; 19 days post irradiation, no more eggs were laid (Fig. 1). Dissections of pseudoparasitized hosts revealed that radiation did cause temporary sterilization of the females. On day 1 post irradiation, 98\% of 405 eggs deposited by wasps that received a dose of $48 \mathrm{~Gy}$ and $100 \%$ of the 358 laid by wasps irradiated at 96 Gy were non-viable. The reproductive capacity recovered; 4 days 


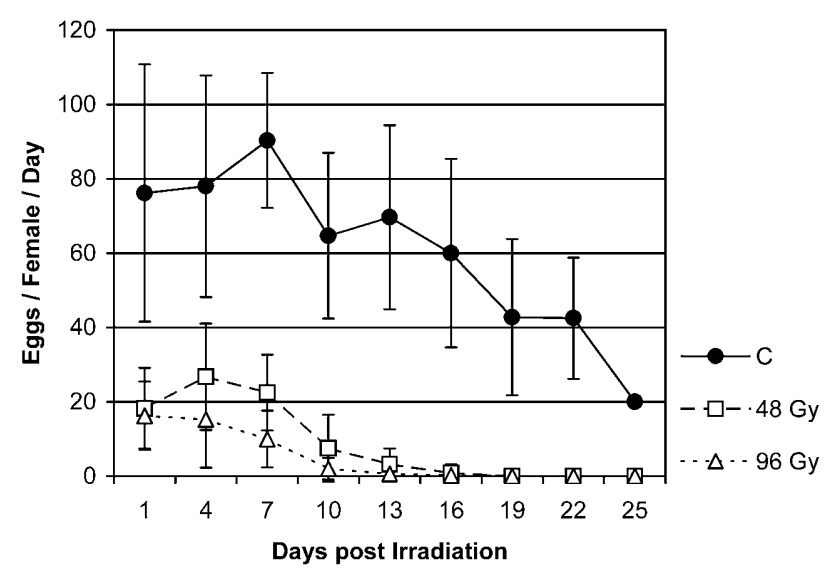

Fig. 1. Number of eggs laid per G. liparidis female per day. Wasps were irradiated with 48 Gy or 96 Gy, 7 to 8 days after eclosion from the cocoon. Untreated wasps of same age served as controls $(=\mathrm{C})$ Means $\pm \mathrm{SD}$.

post irradiation, 38\% (48 Gy) and 33\% (96 Gy) of eggs deposited by irradiated females were viable. However, within each individual host larva, less then $10 \%$ of the parasitoid eggs were viable; nevertheless parasitoids hatching from these eggs were usually able to complete their development. Offspring from irradiated females was exclusively male. All further reported data on the effects of pseudoparasitism stem from host larvae in which no developing parasitoids were found.

\section{Effects of pseudoparasitization on $L$. dispar development}

Pseudoparasitization by irradiated $G$. liparidis affected growth and development of $L$. dispar larvae. Morphological abnormities appeared in the larval stages as well as during metamorphosis. However, $15 \%$ of larvae stung by wasps treated with 24 Gy $(\mathrm{n}=41), 21 \%$ stung by

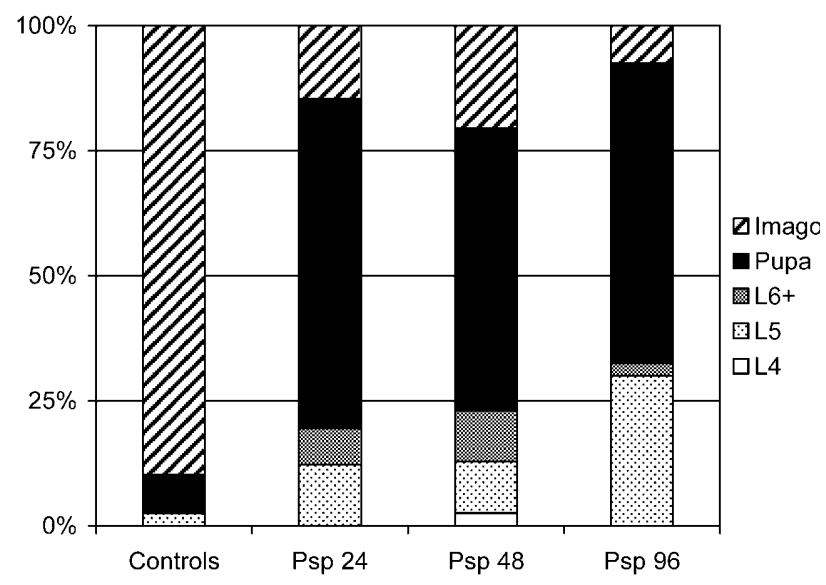

Fig. 2. Percentage of $L$. dispar that either died during the larval stages $(\mathrm{L} 4=4$ th instar, L5 $=5$ th instar, L6 $+=6$ th instar or older) and the pupal stage, respectively, or developed successfully into imagines. Larvae pseudoparasitized by $G$. liparidis irradiated with $24 \mathrm{~Gy}(\mathrm{n}=41), 48 \mathrm{~Gy}(\mathrm{n}=39)$ or 96 Gy $(n=40)$ and unparasitized controls $(n=39)$.

wasps treated with 48 Gy $(n=39)$, and $8 \%$ stung by wasps treated with 96 Gy $(\mathrm{n}=40)$ showed no such symptoms; they pupated and developed into normal adults. This reflects the percentage of larvae stung by untreated $G$. liparidis that developed into adults showing no symptoms of parasitization $(17 \%, \mathrm{n}=41)$. Pseudoparasitized $L$. dispar suffered high mortality during the larval and particularly pupal stages ( 79 to $93 \%$ ), while only $10 \%$ of the controls did not develop into adults (Fig. 2). The mortality in pseudoparasitized L. dispar was regularly connected with developmental abnormities, which rarely occurred in unparasitized insects. $48 \%$ of pseudoparasitized larvae that developed through 6 larval stages showed parts of pupal antennal pads on the larval head capsule in this stage (Fig. 3). Occurrence of this malfor-
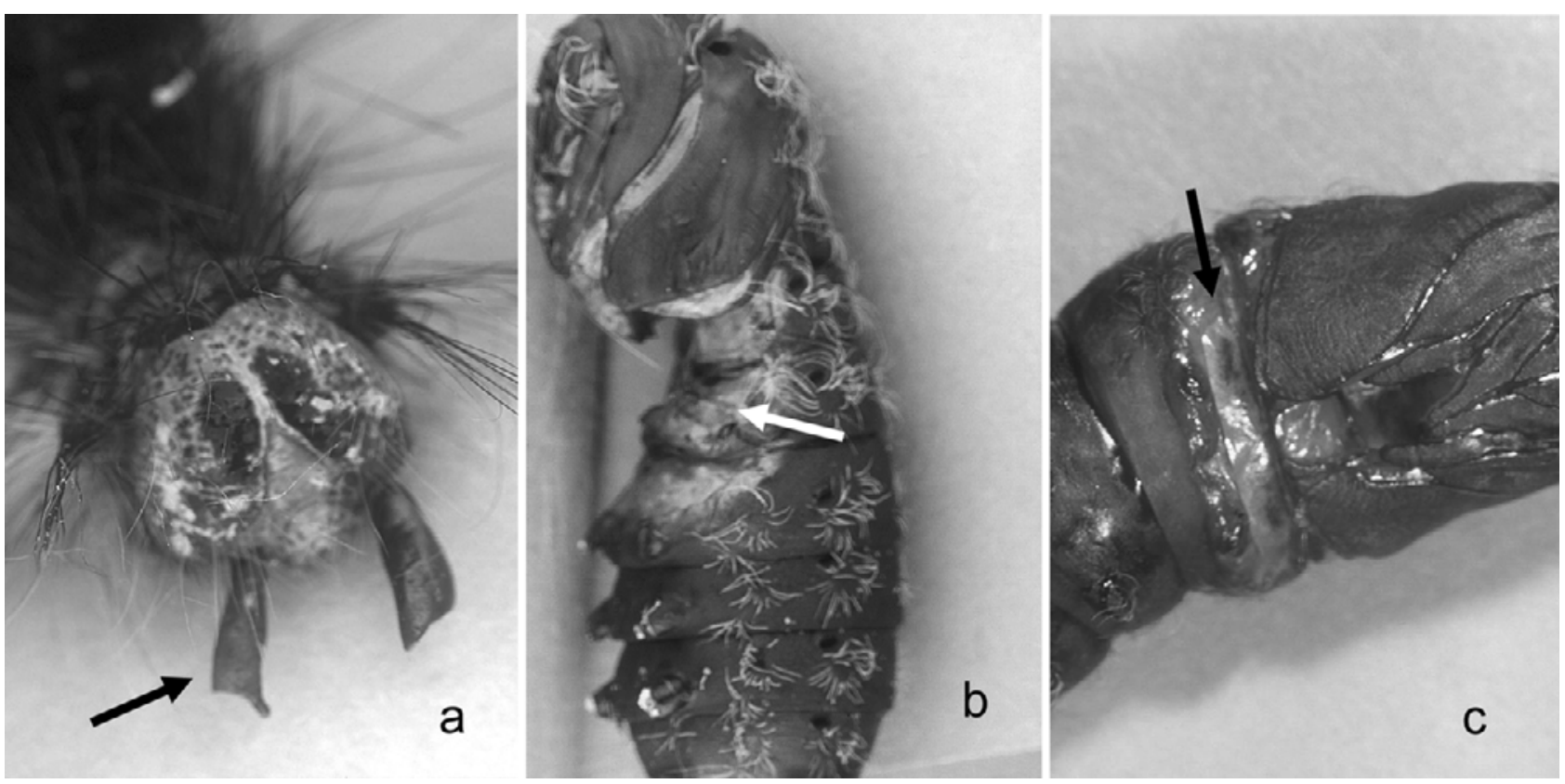

Fig. 3. Developmental abnormities in pseudoparasitized L. dispar: (a) Precocious pupal antennal pads in 6th instar larvae. (b) Pupa with malformed abdominal segments and shortened wing pads. (c) Area with thin, non-sclerotized cuticle is exposed in pseudoparasitized pupa. 


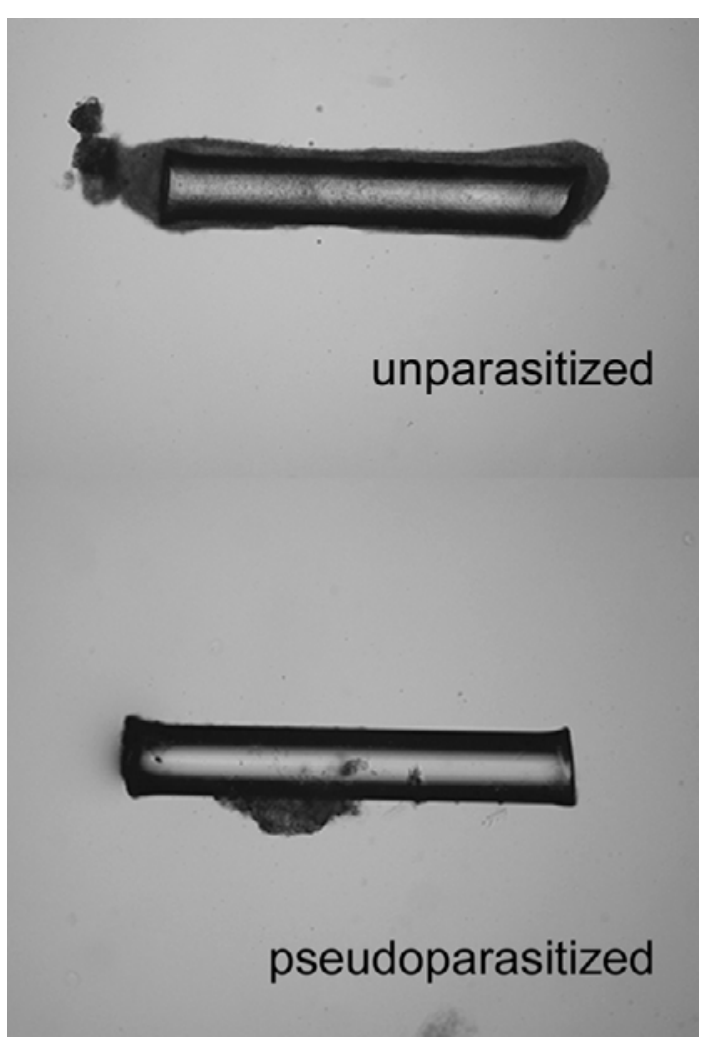

Fig. 4. Hemocytic encapsulation of implanted plastic rods. Unparasitized larvae form a dense, regular capsule around the rods. In pseudoparasitized larvae, hemocytic attachment occurs at much lower level; formed capsules are irregular, large portions of the rod surface are not covered by hemocytes.

mation correlated with mortality during the 6th instar or the larval-pupal molt. Generally, many pathological symptoms occurred during larval-pupal molt of pseudoparasitized L. dispar: Around $20 \%$ of the larvae in each pseudoparasitization treatment suffered from an incomplete molt; e.g., the larval head capsule and/or skin remained attached to the pupa. Only one such case was observed in controls. Although the majority also of pseudoparasitized insects was able to complete the larvalpupal molt, $60-100 \%$ of such pupae showed morphological abnormities. Most frequently the area between thorax and abdomen that is covered only by a thin, nonsclerotized cuticle was exposed in pseudoparasitized larvae (Fig. 3). Normally, this part is covered by the wing pads. Also, cuticular sclerotization was frequently incomplete; pupae were of light brown colour instead of the normal dark brown. Such abnormal pupae either failed to complete metamorphosis or they developed into adults that failed to eclose from the pupal case.

Pseudoparasitized $L$. dispar larvae required longer completing their development than unparasitized larvae. Most pseudoparasitized females developed through six or seven larval instars (53-77\%) while the majority of unparasitized insects developed through five instars (81\%). Fresh mass of the resulting pseudoparasitized pupae was higher (Table 1), both in male and female
TABLE 1. Fresh mass of unparasitized (controls) and pseudoparasitized (stung by $G$. liparidis irradiated with $24 \mathrm{~Gy}, 48$ Gy or $96 \mathrm{~Gy}$ ) $L$. dispar pupae and developmental time until pupation (from time of pseudoparasitization in premolt to $3 \mathrm{rd}$ instar): means $\pm \mathrm{SD}$, different letters within rows indicate significant differences $(\mathrm{P}<0.05)$. Percentage of larvae developing through 5,6 , or 7 instars.

\begin{tabular}{|c|c|c|c|c|c|}
\hline \multicolumn{6}{|l|}{ (A) Males } \\
\hline & & Controls & Psp 24 & Psp 48 & Psp 96 \\
\hline $\begin{array}{l}\text { Fresh mass } \\
(\mathrm{mg})\end{array}$ & 5 & $\begin{array}{c}363 \pm 60 a \\
(\mathrm{n}=17)\end{array}$ & $\begin{array}{c}457 \pm 80 \mathrm{~b} \\
(\mathrm{n}=10)\end{array}$ & $\begin{array}{c}426 \pm 130 a b \\
(n=8)\end{array}$ & $\begin{array}{c}485 \pm 140 a b \\
(n=10)\end{array}$ \\
\hline $\begin{array}{l}\text { Days to } \\
\text { pupation }\end{array}$ & 5 & $\begin{array}{c}29.1 \pm 2.7 \mathrm{a} \\
(\mathrm{n}=17)\end{array}$ & $\begin{array}{c}35.2 \pm 4.1 b \\
(n=10)\end{array}$ & $\begin{array}{c}32.6 \pm 2.3 b \\
(n=8)\end{array}$ & $\begin{array}{c}34.7 \pm 1.8 b \\
(n=10)\end{array}$ \\
\hline $\begin{array}{l}\text { Ratio of } \\
\text { larval instar }\end{array}$ & 5 & $100 \%$ & $100 \%$ & $100 \%$ & $100 \%$ \\
\hline \multicolumn{6}{|l|}{ (B) Females } \\
\hline & & Controls & Psp 24 & Psp 48 & Psp 96 \\
\hline \multirow[t]{4}{*}{$\begin{array}{l}\text { Fresh mass } \\
(\mathrm{mg})\end{array}$} & 5 & $\begin{array}{c}787 \pm 110 a \\
(n=17)\end{array}$ & $\begin{array}{c}967 \pm 78 b \\
(n=6)\end{array}$ & $\begin{array}{c}1014 \pm 120 b \\
(n=3)\end{array}$ & $\begin{array}{c}849 \pm 120 a b \\
(n=4)\end{array}$ \\
\hline & 6 & $\begin{array}{c}826 \pm 330 a \\
(n=4)\end{array}$ & $\begin{array}{c}1056 \pm 530 a \\
(n=4)\end{array}$ & $\begin{array}{c}1236 \pm 430 a \\
(n=7)\end{array}$ & $\begin{array}{c}1259 \pm 350 a \\
(n=6)\end{array}$ \\
\hline & 7 & - & 777 & - & 435 \\
\hline & & - & $(\mathrm{n}=1)$ & - & $(\mathrm{n}=1)$ \\
\hline \multirow[t]{4}{*}{$\begin{array}{l}\text { Days to } \\
\text { pupation }\end{array}$} & 5 & $\begin{array}{c}32.7 \pm 1.3 \mathrm{a} \\
(\mathrm{n}=17)\end{array}$ & $\begin{array}{c}36.2 \pm 1.9 b \\
(n=6)\end{array}$ & $\begin{array}{c}33.7 \pm 1.5 a b \\
(n=3)\end{array}$ & $\begin{array}{c}36.8 \pm 4.1 \mathrm{ab} \\
(\mathrm{n}=4)\end{array}$ \\
\hline & 6 & $\begin{array}{c}43.3 \pm 6.2 a \\
(n=4)\end{array}$ & $\begin{array}{c}47.0 \pm 6.4 a \\
(n=4)\end{array}$ & $\begin{array}{c}44.9 \pm 2.5 \mathrm{a} \\
(\mathrm{n}=8)\end{array}$ & $\begin{array}{c}43.8 \pm 2.8 \mathrm{a} \\
(\mathrm{n}=6)\end{array}$ \\
\hline & 7 & - & 58 & - & 57 \\
\hline & & - & $(n=1)$ & - & $(\mathrm{n}=1)$ \\
\hline \multirow[t]{3}{*}{$\begin{array}{l}\text { Ratio of } \\
\text { larval instar }\end{array}$} & 5 & $81 \%$ & $47 \%$ & $23 \%$ & $29 \%$ \\
\hline & 6 & $19 \%$ & $47 \%$ & $77 \%$ & $64 \%$ \\
\hline & 7 & $0 \%$ & $6 \%$ & $0 \%$ & $7 \%$ \\
\hline
\end{tabular}

insects. There were no significant differences between larvae stung by wasps irradiated at different doses.

\section{Effects of pseudoparasitization on host immune system}

Both, hemocytic and humoral immune reactions of $L$. dispar larvae that had been pseudoparasitized by $G$. liparidis irradiated with 48 Gy were impaired. Plastic rods that were implanted into control larvae became surrounded by a dense, regular hemocyte capsule consisting of several layers of cells. Hemocyte attachment was generally incomplete and irregular in parasitized and pseudoparasitized larvae (Fig. 4). Frequently, only the front sides of the rods showed adhesion of blood cells. Moreover, the hemocyte aggregates did not appear to be solid, they could easily be removed from the rod. The hemocyte attachment was also very variable in parasitized and pseudoparasitized $L$. dispar. In parasitized larvae, $50 \%$ of the rods showed a very low cover by blood cells $(\leq 20 \%$ of the rod surface area covered), $38 \%$ of the cases had a high hemocyte cover ( $\geq 60 \%$ of the surface area). In pseudoparasitized larvae the situation was similar; $42 \%$ with low 


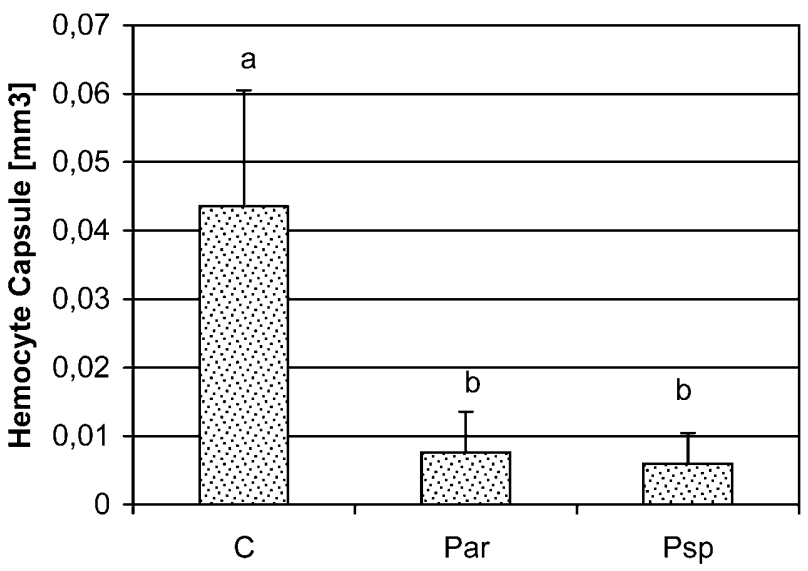

Fig. 5. Volume of hemocyte capsules surrounding implanted plastic rods after five days exposure in the hemocoel of unparasitized $(\mathrm{C}, \mathrm{n}=17)$, parasitized (Par, $\mathrm{n}=16)$ and pseudoparasitized $(\mathrm{Psp}, \mathrm{n}=12)$ L. dispar larvae. Means $\pm \mathrm{SD}$, different letters indicate significant differences between means $(\mathrm{P}<$ $0.05)$.

surface cover vs. $50 \%$ with high cover. On the other hand, all rods from unparasitized larvae showed a high surface cover; in $59 \%$ of the cases the entire surface was covered by hemocytes. These apparent differences in hemocyte attachment were also reflected in significantly lower volumes of the hemocyte aggregations in parasitized and pseudoparasitized larvae compared to unparasitized controls (Fig. 5).

Both, parasitization and pseudoparasitization led to a suppression of the melanization reaction in host hemolymph 3 and 5 days post parasitization. Melanization was still lower in parasitized $L$. dispar larvae 11 days post parasitization while there was no difference between pseudoparasitized and unparasitized larvae (Fig. 6).

\section{DISCUSSION}

Pseudoparasitization by $\gamma$-irradiated $G$. liparidis significantly affected growth and development of $L$. dispar indicating that PDV and venom of the wasp contribute to some modifications of host development observed after normal parasitization by $G$. liparidis (Schopf \& Steinberger, 1996). In other well-studied species, parasitoid associated factors cause developmental arrest or mortality during pupation (Dushay \& Beckage, 1993; Beckage et al., 1994; Soller \& Lanzrein, 1996). Parasitism by the closely related, solitary endoparasitoid, G. porthetriae as well as injection of its purified, PDV-containing calyx fluid induced prolonged larval instars of $L$. dispar (Nussbaumer et al., 2002). G. liparidis parasitism interferes with the juvenile hormone metabolism of $L$. dispar host and leads to elevated hormone titers in the parasitized larva (Schopf et al., 1996). Failure of larval or larvalpupal molts and developmental abnormities as observed in our study, may be indications that $G$. liparidis PDV and venom play a significant role in altering the host's hormone metabolism. It has been shown that parasitoid associated factors from several species can lead to depression of juvenile hormone esterase levels (e.g., Tanaka \&

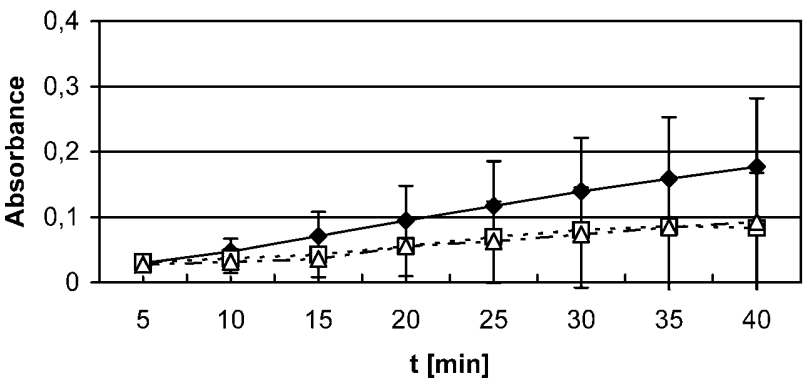

$5 \mathrm{dpp}$

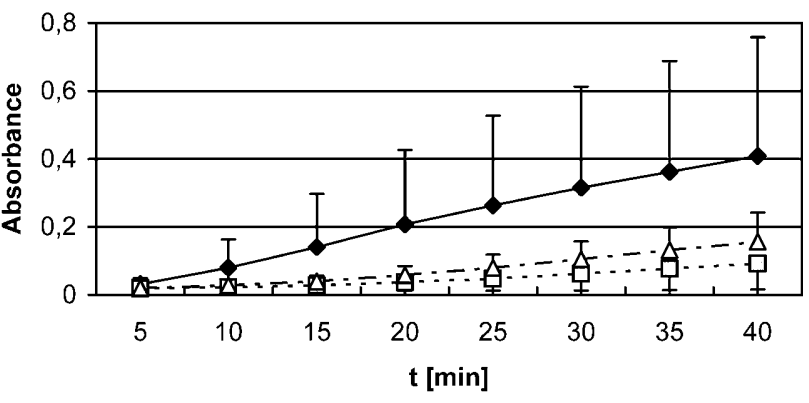

11 dpp

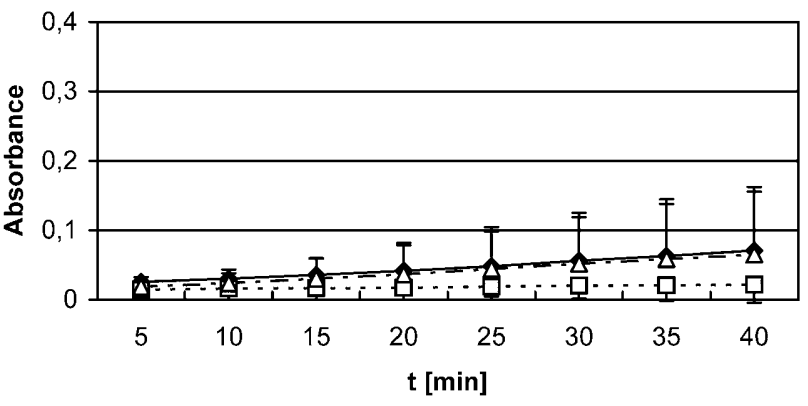

Fig. 6. Melanization of hemolymph as indicated by increasing absorbance at $405 \mathrm{~nm}$ in unparasitized (black diamonds), parasitized (grey squares) and pseudoparasitized (white triangles) $L$. dispar larvae, 3 days $(\mathrm{n}=7 \ldots 12), 5$ days $(\mathrm{n}=10 \ldots 20)$ or 11 days $(n=13 \ldots 20)$ post (pseudo-)parasitism. Means \pm SD.

Vinson, 1991; Grossniklaus-Bürgin et al., 1998; Cusson et al., 2000) as well as elevated juvenile hormone titers (Grossniklaus-Bürgin et al., 1998; Shelby \& Webb, 1999). But also the parasitoid larvae themselves contribute significantly to the hormonal alterations in the host larva (Cole et al., 2002). Jones (1985) and Jones \& Sreekrishna (1984) showed that chemical inhibition of juvenile hormone esterase or administration of juvenile hormone could induce supernumerary larval molts leading to larvae with abnormal caput morphology. Disturbance of juvenile hormone metabolism through pseudoparasitization could be an explanation for the precocious formation of pupal antennae in 6th instar larvae. It could further be responsible for incomplete sclerotization and morphological abnormities in pseudoparasitized L. dispar pupae. Naturally pseudoparasitized T. ni pupae likewise showed short wing pads and 
failure of larval-pupal molt (Jones et al., 1986). However, abnormities of pupae have to be interpreted with caution because they seem to be nonspecific symptoms; they can, e.g., also be caused by nutritional imbalances in the larval diet of L. dispar (Klaus, 1999).

Parasitization and pseudoparasitization led to the expected suppression of host immune response. Hemolymph melanization was reduced as well as the ability of hemocytes to encapsulate foreign objects. It is known from many host-parasitoid systems that polydnavirus and venom cause a broad suppression of the host immune system (e.g., Edson et al., 1981; Strand \& Pech, 1995; Shelby \& Webb, 1999). Melanization is an important constituent of the insect humoral immune system. It starts with activation of prophenoloxidase; the active enzyme, phenoloxidase catalyzes oxidation of phenols to quinones that further polymerize to melanin (Boucias \& Pendland, 1998; Söderhäll \& Cerenius, 1998). G. liparidis parasitism suppressed the activation of the prophenoloxidase system in L. dispar. PDV/venom alone were able to suppress melanization in pseudoparasitized larvae 3 and 5 days post parasitization. At a later stage, also the parasitoid larvae and/or the teratocytes were apparently involved in reducing hemolymph melanization since the levels in pseudoparasitized larvae did not differ from controls any longer. Such temporary immune suppressive effect of PDV has already been demonstrated for Cotesia congregata (Lavine \& Beckage, 1996).

Gamma radiation had an immediate effect on the fecundity of $G$. liparidis females. Already one day after irradiation, the number of eggs laid per female decreased significantly compared to the controls. Oviposition ceased about 1-2 weeks prior to death, although the wasps continued to sting larvae that were offered to them. The irradiation treatment achieved partial sterility of the females. Reduction of fertility increased with the dose; 96 Gy or higher caused $100 \%$ non-viability of eggs laid one day post treatment. An increase in sterility with dose was also observed for the grain beetle Oryzaephilus surinamensis, for which 26 Gy achieved 50\% and 177 Gy achieved 99.9\% sterility (Tuncbilek, 1997). Additionally, maturation of the eggs seems to be an important factor determining the level of sterility in the case of the synovigenic G. liparidis. The fully developed eggs in the ovaries of one week-old females were more severely affected by radiation than eggs in females that were only 1.5 days old at the time of treatment (Tillinger, 2002). Such females laid $30 \%$ fertile eggs already one day post irradiation. Although fertility of the wasps recovered after radiation treatment, the significantly reduced overall fecundity indicates a marked, long-lasting negative impact on the reproductive organs. The filial generation originating from viable eggs of irradiated $G$. liparidis was exclusively male. Although the sex ratio was male biased also in the control groups $(3: 1$ to $8: 1)$, this finding clearly indicates an effect of irradiation. A likely explanation is that sperm stored in the receptaculum seminis of the wasp was damaged by the radiation (the females had mated before treatment). Radiation may also have affected the micropyles of the egg and thus prevented penetration by the spermatozoid. In both cases females would have laid only unfertilized eggs producing only male offspring.

We believe that pseudoparasitization achieved by $\gamma$-irradiation of $G$. liparidis females is a suitable tool for studying physiological interactions between the associated factors of braconid endoparasitoids and their host larvae. A difficulty is the only temporary nature of sterilization. Thus, it is imperative to expose females to radiation with a high number of mature eggs in their ovaries and to use these females for pseudoparasitization on the first day after irradiation. One matter of concern is whether radiation affects the PDV. Comparison of our results with normal parasitism as well as with reports in literature as done above suggests that there seems to be no damage to the virus. Moreover did different doses of radiation not result in different effects of pseudoparasitization on the host. The advantage of the technique is that the administration of PDV and venom by the wasp is done in the natural way during oviposition. The traumatic impact on the host larva is like in natural parasitization minimal and unlike with injection of purified substances with syringes the dosage should represent regular oviposition. Radiation-induced pseudoparasitism will be used to further investigate the role of parasitoid associated factors in the host-parasitoid system L. dispar - G. liparidis.

ACKNOWLEDGEMENTS. We are grateful to Alan Robinson of the FAO/IAEA Agriculture and Biotechnology Laboratory, Seibersdorf, Austria, for irradiation of the parasitoid wasps. Gypsy moth eggs were kindly provided by John Tanner, USDA/APHIS Otis Methods Development Center at Cape Cod, MA, USA. We thank Andrea Stradner, Josef Pennerstorfer, and Petr Zabransky for their technical assistance. This work is part of the FAO/IAEA co-ordinated research project CRP D4.30.02 (project leader: Jorge Hendrichs).

\section{REFERENCES}

BECKAGE N.E. 1997: New insights: how parasites and pathogens alter the endocrine physiology and development of insect hosts. In Beckage N.E. (ed.): Parasites and Pathogens: Effects on Host Hormones and Behavior. Chapman and Hall, New York, pp. 3-36.

Beckage N.E., Tan F.F., Schleifer K.W., Lane R.D. \& CheRUBIN L.L. 1994: Characterization and biological effects of Cotesia congregata polydnavirus on host larvae of the tobacco hornworm, Manduca sexta. Arch. Insect Biochem. Physiol. 26: $165-195$.

Bell R.A., Owens C.D., Shapiro M. \& TardifF J.R. 1981: Mass rearing and virus production. In Doane C.C. \& McManus M.L. (eds): The Gypsy Moth: Research Toward Integrated Pest Management. USDA, Washington, DC. [U.S. Dept. Agric. For. Serv. Tech. Bull. 1584], pp. 599-600.

Boucias D.G. \& Pendland J.C. 1998: Principles of Insect Pathology. Kluwer Academic Publishers, Dordrecht, 537 pp.

Cole T.J., Beckage N.E., Tan F.F., Srinivasan A. \& RamasWAMY S.B. 2002: Parasitoid-host endocrine relations: selfreliance or co-optation? Insect Biochem. Mol. Biol. 32: 1673-1679.

Cusson M., Laforge M., Miller D., Cloutier C. \& Stoltz D. 2000: Functional significance of parasitism-induced suppression of juvenile hormone esterase activity in developmentally 
delayed Choristoneura fumiferana larvae. Gen. Comp. Endocrinol. 117: 343-354.

Dushay M.S. \& Beckage N.E. 1993: Dose-dependent separation of Cotesia congregata-associated polydnavirus effects on Manduca sexta larval development and immunity. J. Insect Physiol. 39: 1029-1040.

Edson K.M., Vinson S.B., Stoltz D.B. \& Summers M.D. 1981: Virus in a parasitoid wasp: suppression of the cellular immune response in the parasitoid's host. Science 211: 582-583.

Federici B.A. \& Bigot Y. 2003: Origin and evolution of polydnaviruses by symbiogenesis of insect DNA viruses in endoparasitic wasps. J. Insect Physiol. 49: 419-432.

Grossniklaus-Bürgin C., Pfister-Wilhelm R., Meyer V., Treiblmayr K. \& Lanzrein B. 1998: Physiological and endocrine changes associated with polydnavirus/venom in the parasitoid-host system Chelonus inanitus-Spodoptera littoralis. J. Insect Physiol. 44: 305-321.

Носн G. \& Schорғ A. 2001: Effects of Glyptapanteles liparidis (Hym.: Braconidae) parasitism, polydnavirus, and venom on development of microsporidia infected and uninfected Lymantria dispar (Lep.: Lymantriidae) larvae. J. Invertebr. Pathol. 77: 37-43.

Hoch G., Zubrik M., Novotny J. \& Schopf A. 2001: The natural enemy complex of the gypsy moth, Lymantria dispar (Lep., Lymantriidae) in different phases of its population dynamics in eastern Austria and Slovakia - a comparative study. $J$. Appl. Entomol. 125: 1-11.

JONES D. 1985: Parasite regulation of host insect metamorphosis: a new form of regulation in pseudoparasitized larvae of Trichoplusia ni. J. Comp. Physiol. (B) 155: 583-590.

Jones D. \& SREekrishna S. 1984: Precocious metamorphosis in Chelonus parasitized Trichoplusia ni: the endocrine basis for this anti-juvenile hormone effect. In Borkovec A. \& Thomas T.J. (eds): Insect Neurochemistry and Neurophysiology. Plenum Press, New York, pp. 389-391.

Jones D., Jones G., Rudnicka M., Click A., Reck-Malleczewen V. \& Iwaya M. 1986: Pseudoparasitism of host Trichoplusia ni by Chelonus spp. as a new model system for parasite regulation of host physiology. J. Insect Physiol. 32: 315-328.

KLAus A. 1999: Influence of Food Quality on Development and Pathogen-Induced Mortality of L. dispar L. Thesis, University Vienna, Austria, 64 pp. (in German, English abstr.).

Lavine M.D. \& Beckage N.E. 1995: Polydnaviruses: Potent mediators of host insect immune dysfunction. Parasitology Today 11: 368-378.

LAVINE M.D. \& BeCKAGE N.E. 1996: Temporal pattern of parasitism-induced immunosuppression in Manduca sexta larvae parasitized by Cotesia congregata. J. Insect Physiol. 42: 41-51.

LAWRENCE P.O. \& LANZREIN B. 1993: Hormonal interactions between insect endoparasitoids and their host insects. In Beckage N.E., Thompson S.N. \& Federici B.A. (eds): Parasites and Pathogens of Insects. Vol. 1. Academic Press, San Diego, pp. 59-86.
Nussbaumer C., Stradner A. \& Schopf A. 2002: Effects of parasitization or injection of parasitoid-derived factors from the endoparasitic wasp Glyptapanteles liparidis (Hym., Braconidae) on the development of the larval host, Lymantria dispar (Lep., Lymantriidae). J. Appl. Entomol. 126: 1-7.

Schopf A. 1991: The effect of host age of Lymantria dispar larvae (Lep.: Lymantriidae) on the development of Glyptapanteles liparidis (Hym.: Braconidae). Entomophaga 36: 593-604.

ScHopf A. \& Hoch G. 1997: Bionomics and the significance of Glyptapanteles liparidis (Hym., Braconidae) as a regulator of Lymantria dispar (Lep., Lymantriidae) in different host population densities (in German, English abstr.). J. Appl. Entomol. 121: 195-203.

Schopf A. \& Steinberger P. 1996: The influence of the endoparasitic wasp Glyptapanteles liparidis (Hymenoptera: Braconidae) on the growth, food consumption, and food utilization of its host larva, Lymantria dispar (Lepidoptera: Lymantriidae). Eur. J. Entomol. 93: 555-568.

Schopf A., Nussbaumer C., Rembold H. \& Hammock B.D. 1996: Influence of the braconid Glyptapanteles liparidis on the juvenile hormone titer of its larval host, the gypsy moth, Lymantria dispar. Arch. Insect Biochem. Physiol. 31: 337-351.

Shelby K.S. \& Webв B.A. 1999: Polydnavirus-mediated suppression of insect immunity. J. Insect Physiol. 45: 507-514.

Soller M. \& Lanzrein B. 1996: Polydnavirus and venom of the egg-larval parasitoid Chelonus inanitus (Braconidae) induce developmental arrest in the prepupa of its host Spodoptora littoralis (Noctuidae). J. Insect Physiol. 42: 471-481.

SöDERHÄLl K. \& CerEnius L. 1998: Role of the prophenoloxidase-activating system in invertebrate immunity. Curr. Opin. Immunol. 10: 23-28.

StRAND M.R. \& PeCh L.L. 1995: Immunological basis for compatibility in parasitoid-host relationships. Annu. Rev. Entomol. 40: 31-56.

TANAKA T. \& VInSON S.B. 1991: Depression of prothoracic gland activity of Heliothis virescens by venom and calyx fluids from the parasitoid, Cardiochiles nigriceps. J. Insect Physiol. 37: 139-144.

TILlinger N.A. 2002: The Effect of Different Doses of Cobalt Radiation on the Function of Associated Polydnavirus in the Host-Parasitoid System Lymantria dispar (Lep., Lymantriidae) and Glyptapanteles liparidis (Hym., Braconidae) Thesis, University Vienna, Austria, 152 pp. (in German, English abstr.).

TunCBILEK A.S. 1997: Susceptibility of the saw-toothed grain beetle, Oryzaephilus surinamensis (L.), to gamma radiation. $J$. Stored Prod. Res. 33: 331-334.

Whitfield J.B. \& Asgari S. 2003: Virus or not? Phylogenetics of polydnaviruses and their wasp carriers. J. Insect Physiol. 49: 397-405.

Willers D. \& Lehmann-Danzinger H. 1984: Survival of endoparasitic Hymenoptera in pupae of Lepidoptera by inhibition of phenol oxidase (in German, English abstr.). Z. Parasitenkd. 70: $403-414$.

Received August 23, 2003; revised December 15, 2003; accepted January 21, 2004 